JURNAL ILMIAH KOMPUTER GRAFIS, Vol.14, No.1, Juli 2021, pp. 68 - 78

p-ISSN : 1979-0414(print)

e-ISSN : 2621-6256 (online)

http://journal.stekom.ac.id/index.php/pixel

- page 68

\title{
Desain Web E-Commerce Berbasis Blogspot sebagai Media Promosi Butik Berkah Hijab Kendal
}

Yayuk Kurniawati ${ }^{1}$, Muhammad Sholikhan ${ }^{2}$

${ }^{1}$ Universitas Sains dan Teknologi Komputer Semarang

Jl. Majapahit 605 Semarang, e-mail: yayukkurnia961@gmail.com

${ }^{2}$ Progdi Desain Grafis Universitas Sains dan Teknologi Komputer Semarang

Jl. Majapahit 605 Semarang, e-mail: sholikhan@stekom.ac.id

\section{ARTICLE INFO}

Article history:

Received 30 Mei 2021

Received in revised form 2 Juni 2021

Accepted 10 Juni 2021

Available online july 2021

\section{ABSTRACT}

In this digital era, business competition is increasingly competitive. A business is required to conduct continuous evaluation. In today's business world, e-commerce is a necessity to increase business competition and product sales. In the use of ecommerce, buying and selling and marketing activities will be easier and more efficient where consumers will find it easier to buy and sell the desired goods without having to leave the house so as to show the ease of transactions, reduce costs and speed up the transaction process. This study aims to create a Blogspot-Based E-Commerce Web Design as a Promotional Media for Kendal Hijab Blessing Boutique. It is hoped that the design and development of an e-commerce blog can help business actors to market their products more broadly so that they can increase sales and make it easier for consumers to transact, especially at the Kendal Hijab Berkah Boutique.

Keywords: Desain Web, E-Commerce, Blog, Promosi

\section{Pendahuluan}

Dalam perkembangan dunia usaha ini, banyak timbul persaingan bisnis yang semakin kompetitif. Dimana suatu bisnis dituntut tidak sekedar menerapkan berbagai strategi saja tetapi juga perlu melakukan evaluasi terus menerus. Hal ini lah yang membuat suatu bisnis harus memperbaiki kegiatan pemasarannya agar mampu mencapai tujuan yang ditetapkannya.

Pada era digital seperti saat ini, perkembangan teknologi informasi sangat berperan dalam dunia perekonomian, khususnya pada bidang pemasaran. Proses jual beli tidak hanya bisa dilakukan secara nyata tetapi lebih banyak memanfaatkan dunia digital dengan media internet, yang sering disebut dengan istilah e-commerce (electronic commerce) atau toko online. E-commerce sendiri merupakan sebuah proses terjadinya jual beli produk secara elektronik oleh konsumen dengan perantara komputer atau perangkat lain yang terhubung dengan internet.

Media yang dapat digunakan dalam aktivitas e-commerce adalah world wide web internet salah satunya yaitu blog. Karena sederhana, murah dan mudah, blog banyak dimanfaatkan untuk melakukan kegiatan bisnis. Hal ini tentu mendukung terbentuknya masyarakat berjiwa entrepreneur. Di sisi lain, banyak yang membagi ilmu dan pengalamannya dalam berbisnis di blog pribadinya. Beberapa tokoh dalam perekonomian Indonesia juga banyak berwacana via blog. Pada tingkat korporasi, beberapa perusahaan juga telah memanfaatkan blog sebagai media guna berinteraksi dengan konsumennya. 
Dalam dunia bisnis saat ini e-commerce merupakan suatu kebutuhan untuk meningkatkan serta memenangkan persaingan bisnis dan penjualan produk. Dalam penggunaan media sosial ecommerce kegiatan jual beli maupun pemasaran akan lebih mudah dan efisien dimana konsumen akan lebih mudah melakukan jual beli barang yang diinginkan tanpa harus keluar rumah sehingga memperlihatkan adanya kemudahan bertransaksi, pengurangan biaya dan mempercepat proses transaksi.

Objek penelitian yang saat ini Penulis bahas yaitu usaha rumahan pada Butik Berkah Hijab yang terletak di Kabupaten Kendal. Butik Berkah Hijab sendiri merupakan suatu bidang usaha yang menjual berbagai macam hijab masa kini dari anak kecil hingga orang dewasa. Hijab merupakan hal yang wajib bagi semua kaum wanita muslimah dimana ketertarikan kaum wanita muslim untuk menggunakan hijab sangatlah tinggi, terutama dikalangan remaja, khususnya bagi mahasiswi. Hijab bukanlah suatu hal yang rumit, namun sudah menjadi style bagi kalangan remaja muslim untuk menampilkan ciri khas dengan menggunakan hijab mereka tetap cantik dan tidak meninggalkan norma-norma dalam agama. Berbagai macam model hijab baik hijab segiempat, pashmina, hijab instan, hijab bergo, pashmina instan pun bermunculan demi memikat perhatian kaum wanita untuk melengkapi segala aktivitas, mulai dari aktivitas di rumah, di kampus, jalanjalan, olahraga, hingga acara kondangan maupun acara resmi.

Berdasarkan uraian dan beberapa permasalahan diatas, maka penulis berupaya untuk memecahkan permasalahan yang kemudian akan dirangkum dalam penelitian dengan judul "Desain Web E-Commerce Berbasis Blogspot sebagai Media Promosi Butik Berkah Hijab Kendal". Diharapkan dengan adanya perancangan dan pembangunan blog e-commerce dapat membantu Pelaku Usaha untuk memasarkan produknya yang lebih luas sehingga dapat meningkatkan penjualan dan lebih memudahkan konsumen bertransaksi, terutama pada Butik Berkah Hijab Kendal.

\section{Metode Penelitian}

Sumber masalah di dalam penelitian ini adalah bagaimana membuat web e-commerce pada Butik Berkah Hijab Kendal yang digunakan sebagai media promosi. Dengan adanya masalah tersebut penelitian ini diharapakan menjadi jawaban atau solusi dari hal tersebut.

\subsection{Pengambilan Data}

Metode dalam pengumpulan data penelitian ini menggunakan pendekatan kualitatif, dalam pengumpulan data dilakukan dengan wawancara dengan pemilik Butik Berkah Hijab Kendal. Data pokok dalam penelitian ini berupa foto-foto produk hijab berdasarkan kategori jenis produk maupun berdasarkan merk produk. Foto produk hijab ini juga dilengkapi dengan daftar harga sehingga nantinya memudahkan calon pembeli untuk menentukan pilihannya. Sedangkan data pendukung berupa alamat Butik Berkah Hijab Kendal, titik lokasi map, juga alamat marketplace Butik Berkah Hijab Kendal.

\subsection{Kerangka Berpikir}

Kerangka berpikir merupakan suatu proses yang menjelaskan garis besar dari alur atau logika berjalannya sebuah penelitian. Kerangka berpikir dibuat berdasarkan permasalahan penelitian serta menjelaskan hubungan antar beberapa konsep sehingga terbentuk sebuah penelitian. Berikut merupakan kerangka berfikir dari Desain E-Commerce Berbasis Blog sebagai Media Promosi pada Butik Berkah Hijab Kendal : 


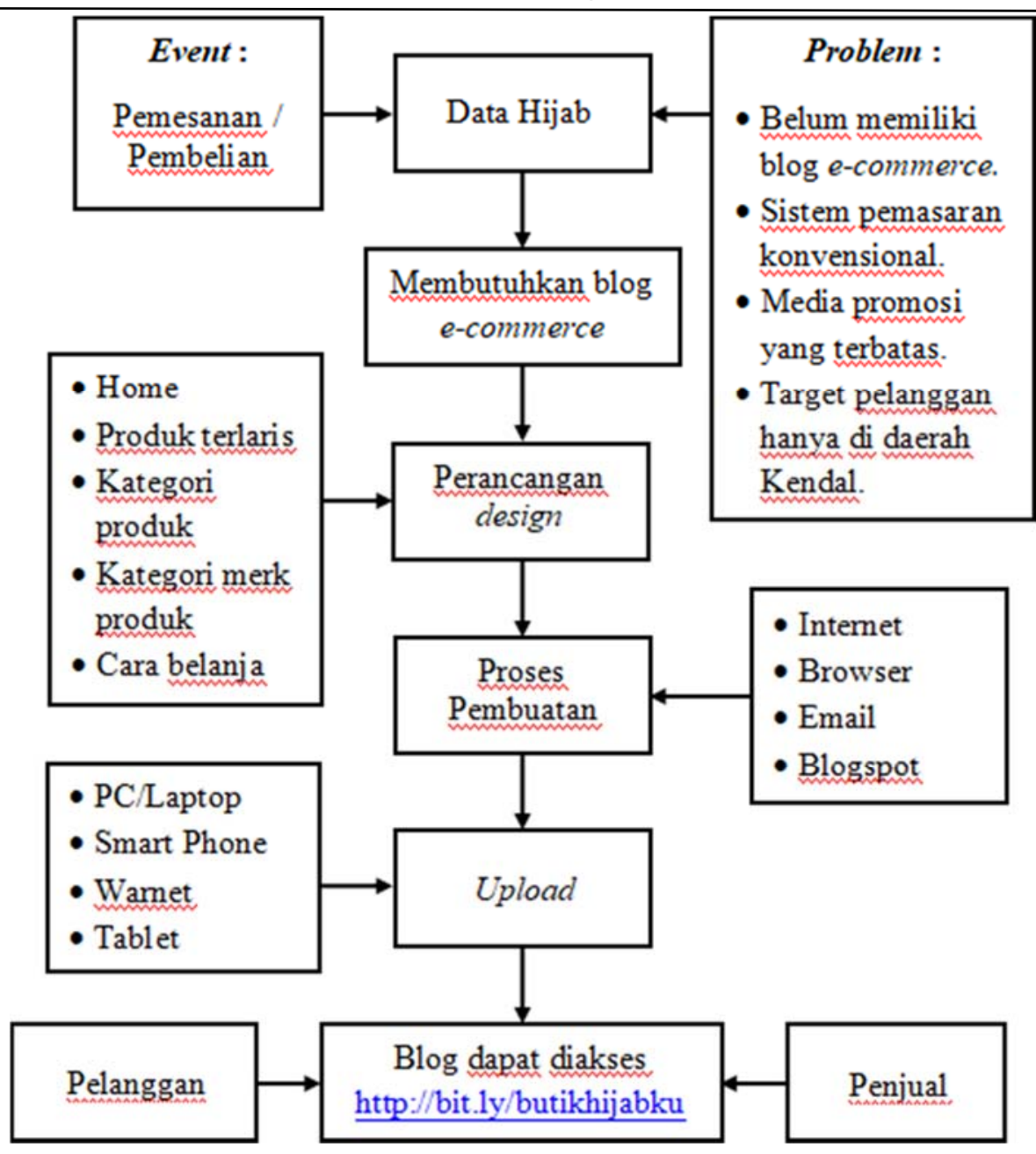

Gambar 1. Kerangka Pemikiran

\subsection{Perancangan E-commerce}

Peneliti seakan merancang sebuah blog e-commerce pada Butik Berkah Hijab yang bertujuan untuk meningkatkan efektivitas dan efisiensi penjualan produk hijab serta mempermudah pelanggan bertransaksi dengan lebih nyaman tanpa harus keluar rumah sehingga dapat mengurangi biaya dan mempercepat proses transaksi. Perancangan dan pembangunan blog e-commerce pada Butik Berkah Hijab ini dilakukan dengan menggunakan tools utama yaitu blogspot, dengan registrasi menggunakan akun Email pada awal pembuatan blog.

Dalam spesifikasi produk yang dikembangkan maka sebelum merancang dan membangun sebuah blog harus ada sketsa atau layout terlebih dahulu guna mempertimbangkan perancangan blog dengan lebih baik, yaitu sebagai berikut : 


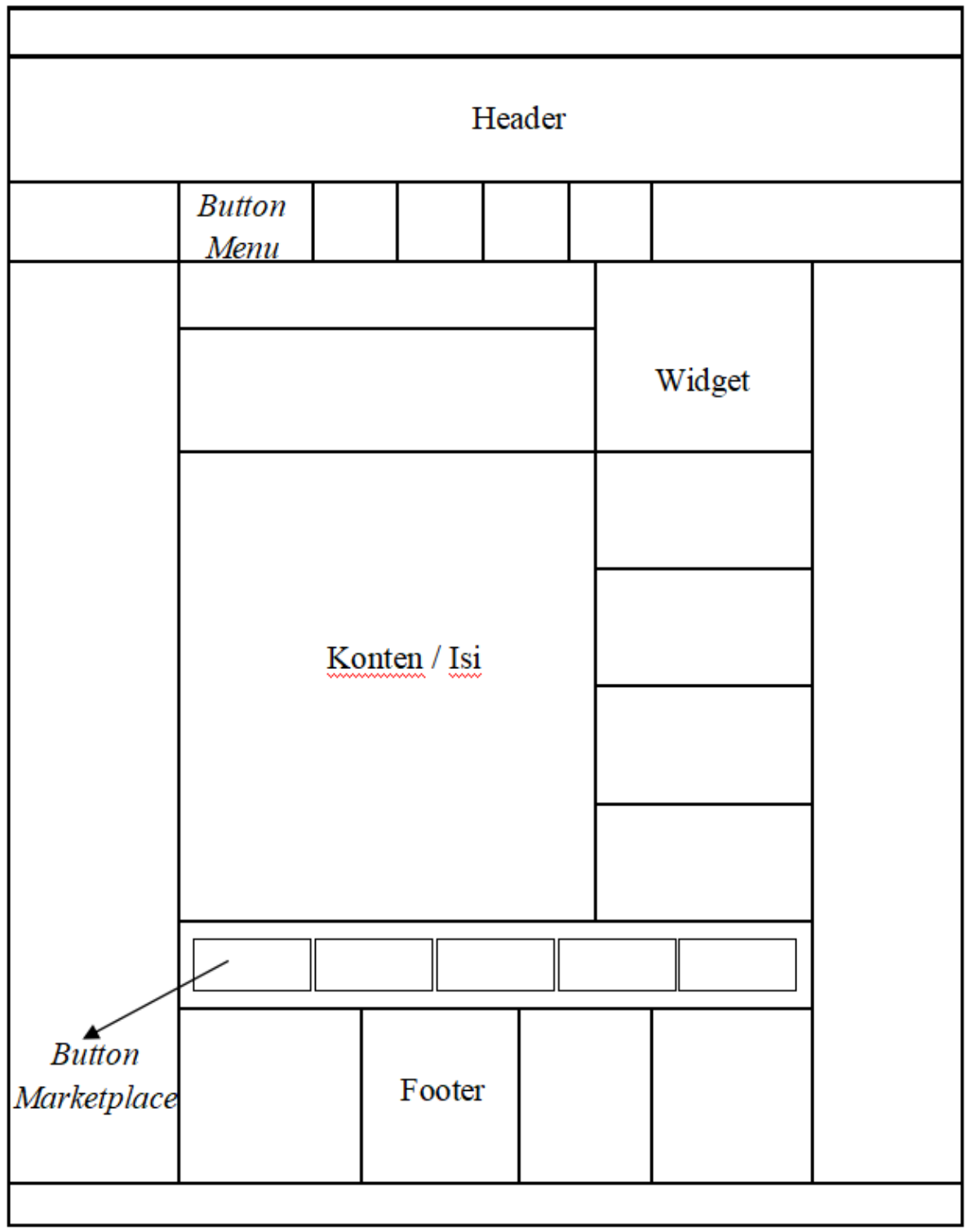

Gambar 2. Perancangan Blog E-Commerce

Perancangan dan pembangunan blog e-commerce pada Butik Berkah Hijab hanya membatasi beberapa hal diantaranya blog ini lebih dikhususkan sebagai sarana promosi dan transaksi pada Butik Berkah Hijab. Desain analisis halaman utama blog terbagi dalam beberapa bagian yaitu :
a. Header
Pada header ditampilkan nama atau logo toko dan identitas toko.

b. Konten atau Isi

Bagian konten berisi produk sebanyak 9 foto produk per halamannya, dengan ukuran foto produk 200 x 200 pixel. Dimana bagian atas konten terdapat deskripsi toko dan banner toko yang berjalan.

c. Button Menu dan Button Marketplace 
Button marketplace terdiri dari 5 button yaitu Facebook, Instagram, Shopee, Bukalapak dan Tokopedia. Sedangkan button menu terdiri dari :

1) Home

Tampilan utama yang berisi produk dan promo terbaru dari Butik Berkah Hijab.

2) Produk Terlaris

Produk terlaris yaitu produk yang selalu dicari pelanggan atau produk yang sering diklik sehingga akan muncul pada widget produk terlaris.

3) Kategori Produk

Kategori produk merupakan pembagian jenis hijab seperti hijab pashmina, bergo, khimar, hijab instan, dan inner hijab.

4) Kategori Merk Produk

Kategori merk produk merupakan pembagian jenis merk hijab seperti Aden, Alareta, Ar Rafi, Daffa Hijab, Denay, Es-Ha Scarf, Lily, dan sebagainya.

5) Cara belanja

Cara belanja yaitu menu dimana pelanggan dapat memahami bagaimana cara memesan atau membeli hijab sesuai dengan prosedur yang ada.

d. Footer

Bagian ini ditampilkan pengecekan resi pengiriman, ucapan terimakasih untuk pelanggan yang sudah mengunjungi dan berbelanja di Butik Berkah Hijab, alamat serta peta lokasi Butik Berkah Hijab. Di bagian paling bawah juga terdapat button WhatsApp melayang yang akan selalu mengikuti apabila scrool digerakkan ke atas dan ke bawah.

e. Widget

Berisi informasi tambahan mengenai data owner dan rekening bank, produk terlaris, kategori produk serta kategori merk produk.

\section{Hasil dan Pembahasan}

\subsection{Halaman Login}

Halaman login merupakan proses mengakses komputer dengan memasukkan identitas dari akun pengguna dan kata sandi guna mendapatkan hak akses untuk menggunakan komputer tersebut. Dimana untuk mengakses halaman blog atau membuat blog, terlebih dahulu ditujukan ke halaman login dengan memasukkan username akun Gmail beserta dengan passwordnya.

\subsection{Halaman Dashboard}

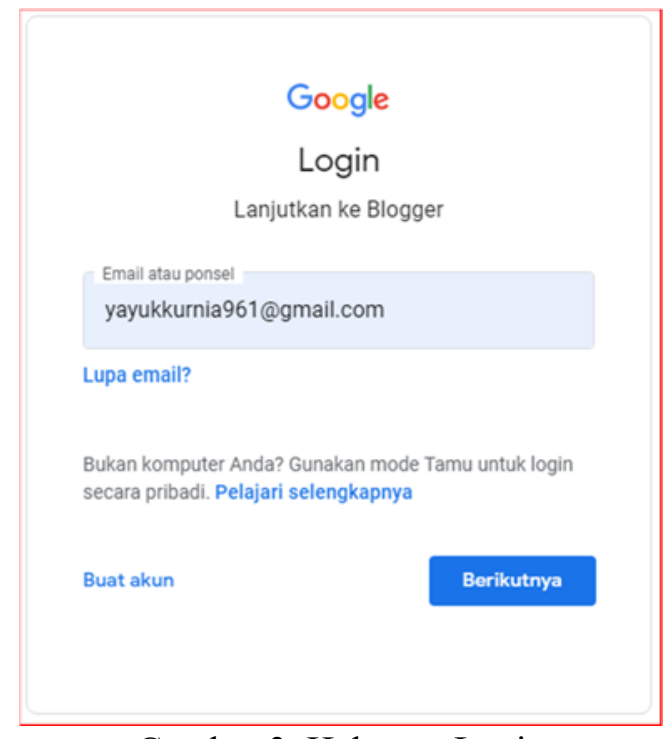

Gambar 3. Halaman Login

Halaman dashboard merupakan halaman utama setelah kita melakukan login. Laman ini memuat informasi penting berupa notifikasi pembaruan dan ringkasan shortcut yang bisa 
mempermudah dalam bekerja. Pada Blog, laman ini berisi menu Postingan, Statistik, Komentar, Penghasilan, Halaman, Tata Letak, Tema, Setelan, Daftar Bacaan dan Lihat Blog.

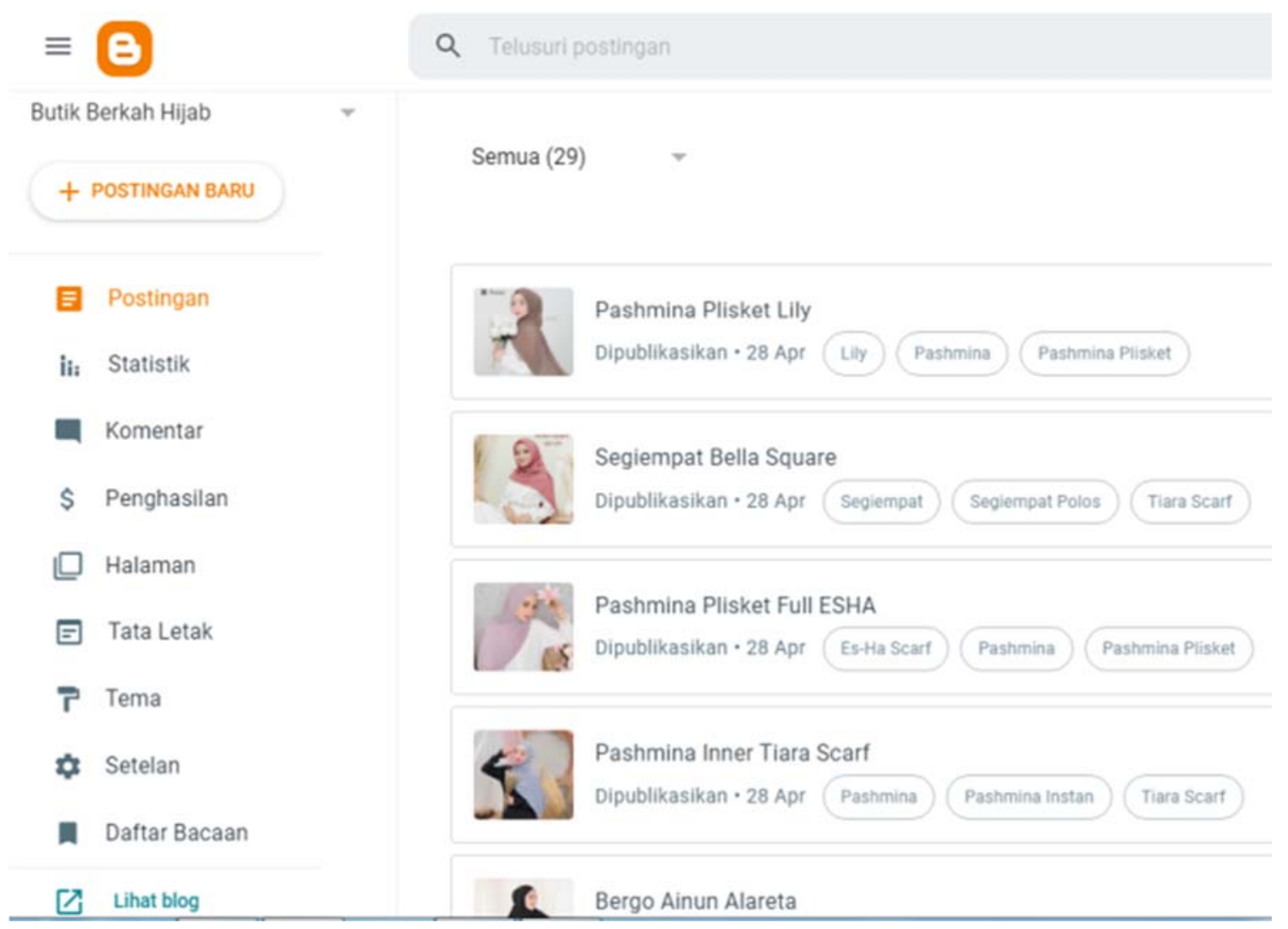

Gambar 4. Halaman Dashboard

\subsection{Halaman Utama Blog Butik Berkah Hijab}

Halaman utama blog merupakan halaman yang akan terlihat pertama kali ketika pelanggan mengunjungi blog Butik Berkah Hijab. Yang tersusun sebagai berikut :

a. Tampilan Header

Pada header di bagian paling atas ditampilkan jam operasional dan alamat E-mail serta nomor telepon dari owner Butik Berkah Hijab Kendal. Sedangkan header bagian bawah ditampilkan logo atau nama toko serta kolom pencarian untuk mencari produk hijab yang diinginkan

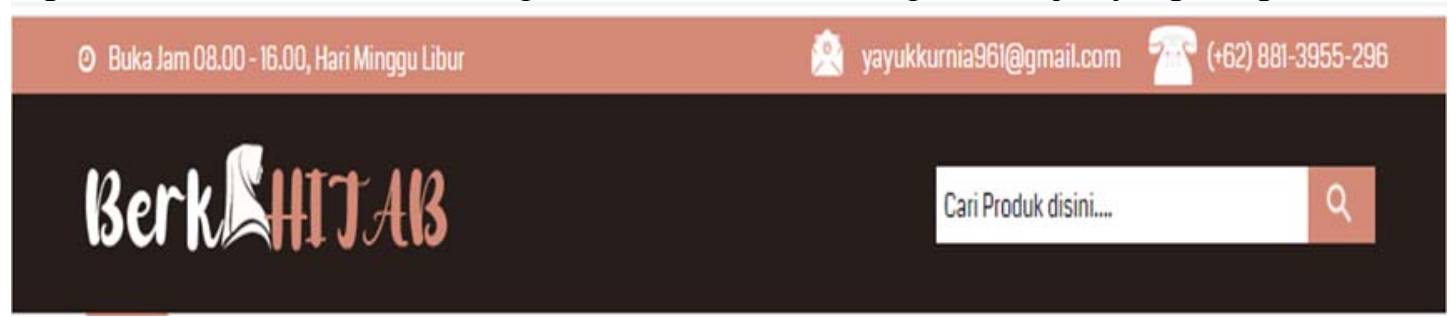

Gambar 5. Tampilan Header

b. Tampilan Menu

Desain Web E-Commerce Berbasis Blogspot sebagai Media Promosi Butik Berkah Hijab Kendal.

(Yayuk Kurniawati) 
Berisi button menu yang terdiri dari Home, Produk Terlaris, Kategori Produk, Kategori Merk Produk, dan button Cara Belanja.

HOME PRODUK TERLAFIS $\sim \quad$ KATEGOHI PRODUK $\sim \quad$ KATEGOHI MERK PRODUK $\sim \quad$ F CARA BELANIA

Gambar 6. Tampilan Menu

c. Tampilan Deskripsi dan Banner

Dibagian bawah menu ditampilkan sebuah deskripsi Butik Berkah Hijab dan Banner yang berisi promo, kategori produk serta nama Butik Berkah Hijab di beberapa marketplace.

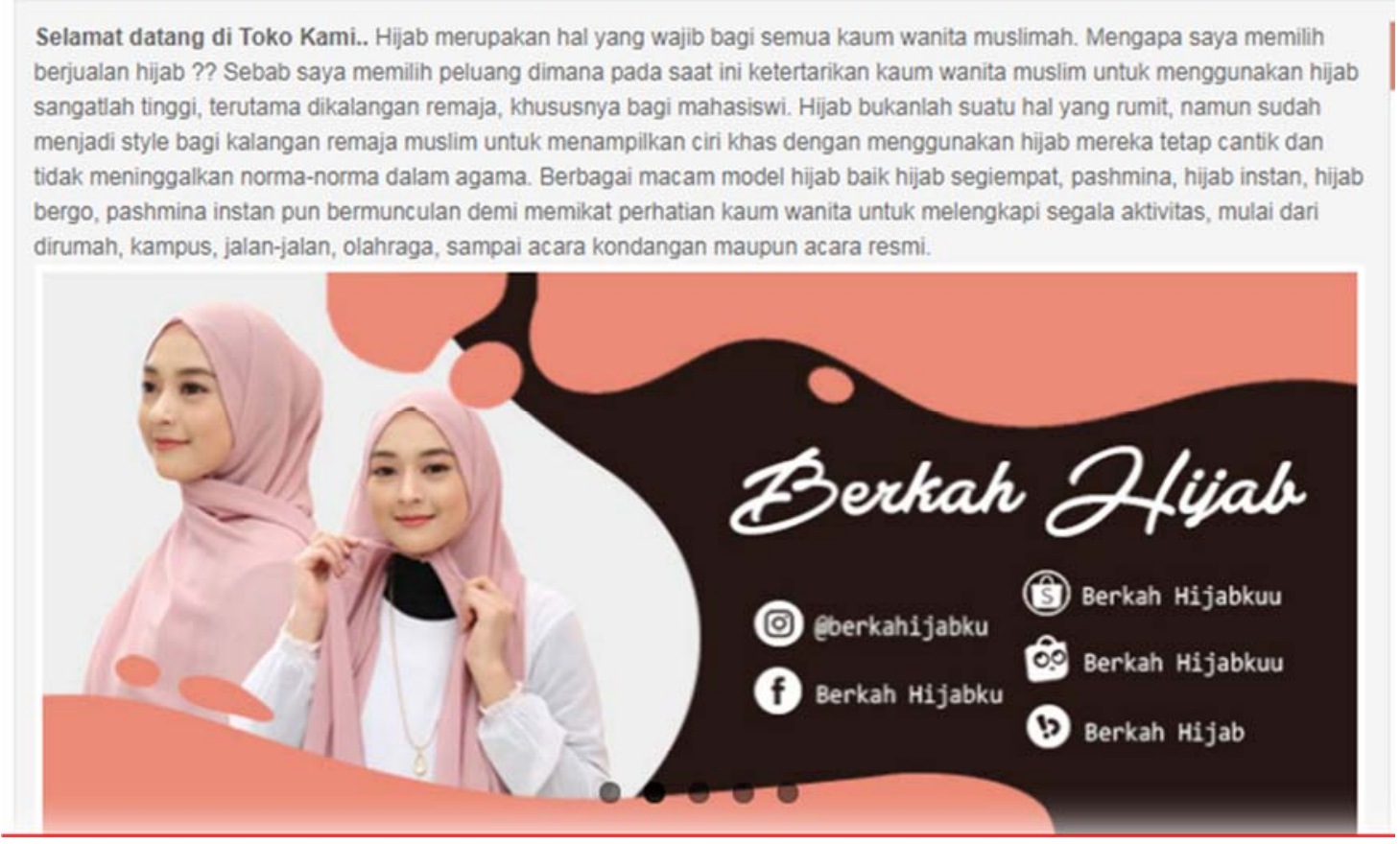

Gambar 7. Tampilan Deskripsi dan Banner

d. Tampilan Widget

Dibagian kanan blog terdapat tampilan widget yang menampilkan data dan foto owner Butik Berkah Hijab, rekening bank owner, produk terlaris, kategori produk serta kategori merk produk. 


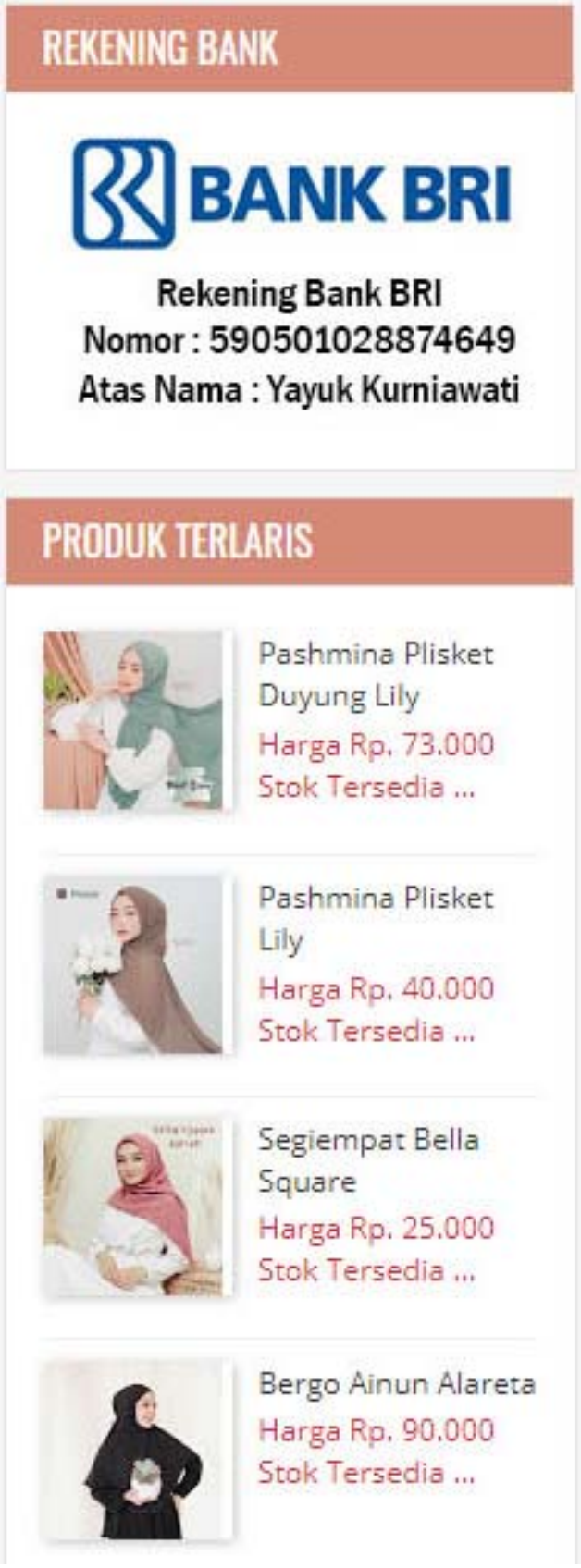

\section{KATEGORI PRODUK}

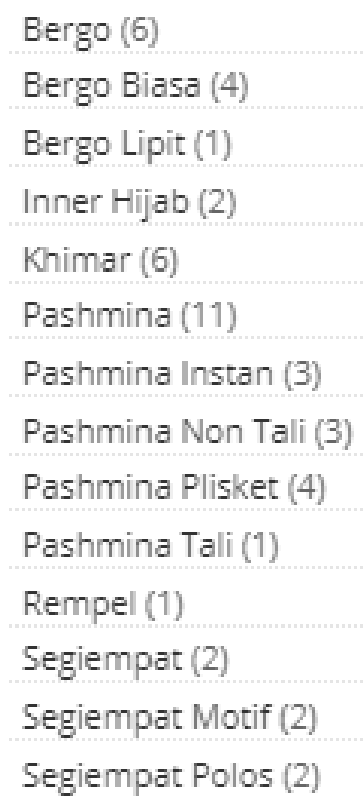

\section{KATEGORI MERK PRODUK}

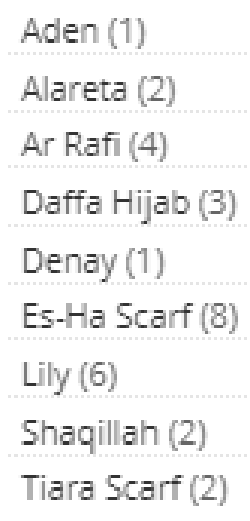

Gambar 8. Tampilan Widget

e. Tampilan Konten atau Isi Blog

Berisi produk dari butik berkah hijab yang berupa hijab dewasa hingga anak-anak seperti hijab pashmina, hijab bergo, hijab instan, khimar dan lain sebagainya. 


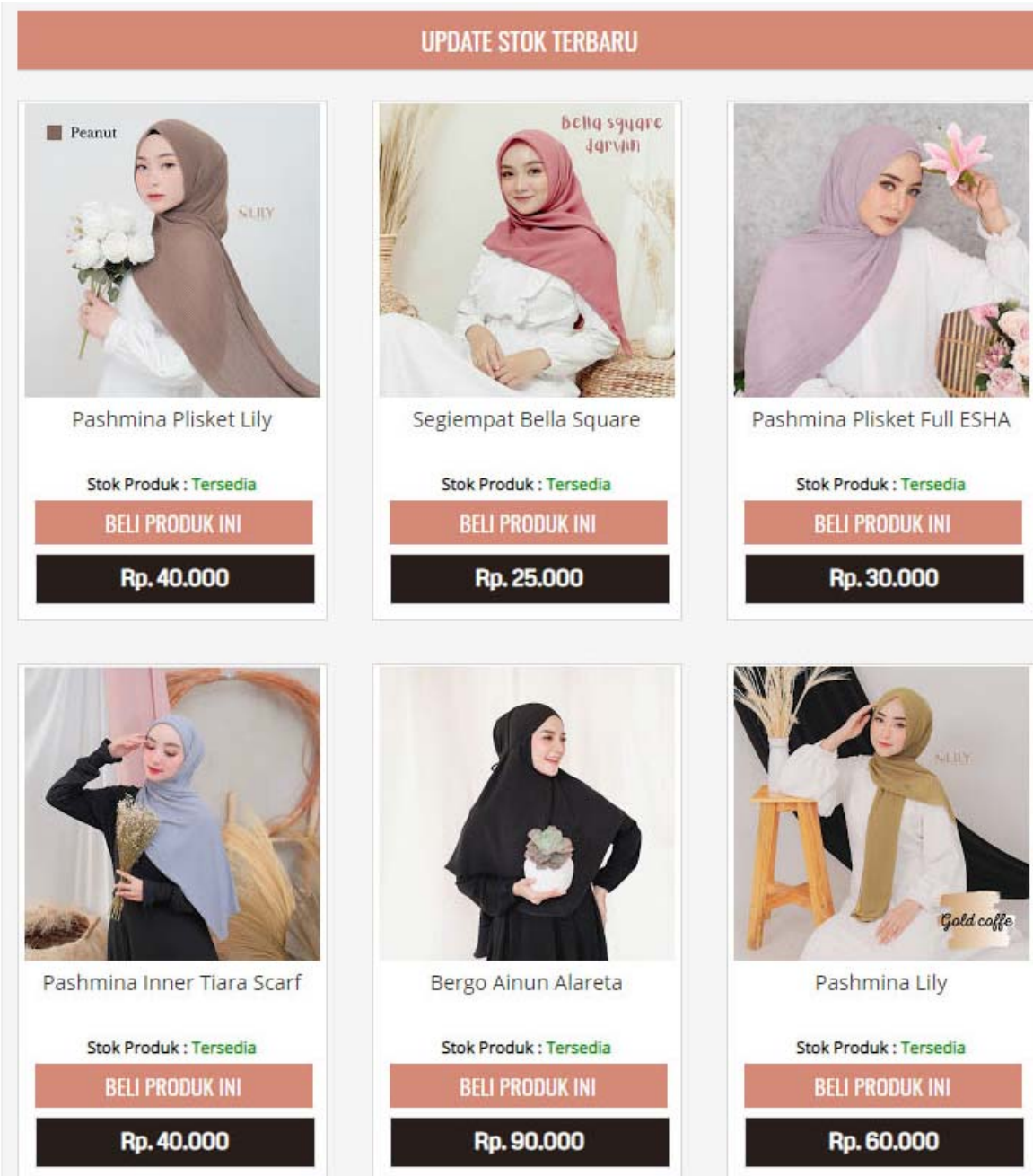

Gambar 9. Tampilan Konten atau Isi Blog

f. Tampilan Button Marketplace

Bagian bawah konten atau isi terdapat button marketplace yang terdiri dari Instagram, Facebook, Shopee, Tokopedia dan Bukalapak.

\section{TEMUKAN TOKO KAMIDI:}

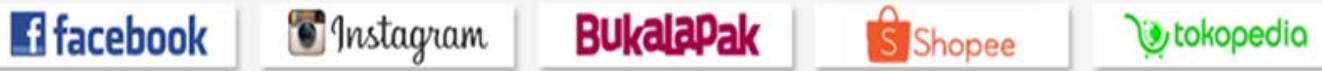

Gambar 10. Tampilan Button Marketplace

g. Tampilan Footer dan WhatsApp Melayang

Di bagian paling bawah terdapat footer yang berisi cek resi pengiriman, ucapan terimakasih untuk pelanggan, alamat, serta lokasi Butik Berkah Hijab. Untuk pemesanan produk atau ingin menanyakan produk ke penjual disediakan tampilan whatsapp melayang yang terdapat dibagian paling bawah blog. 


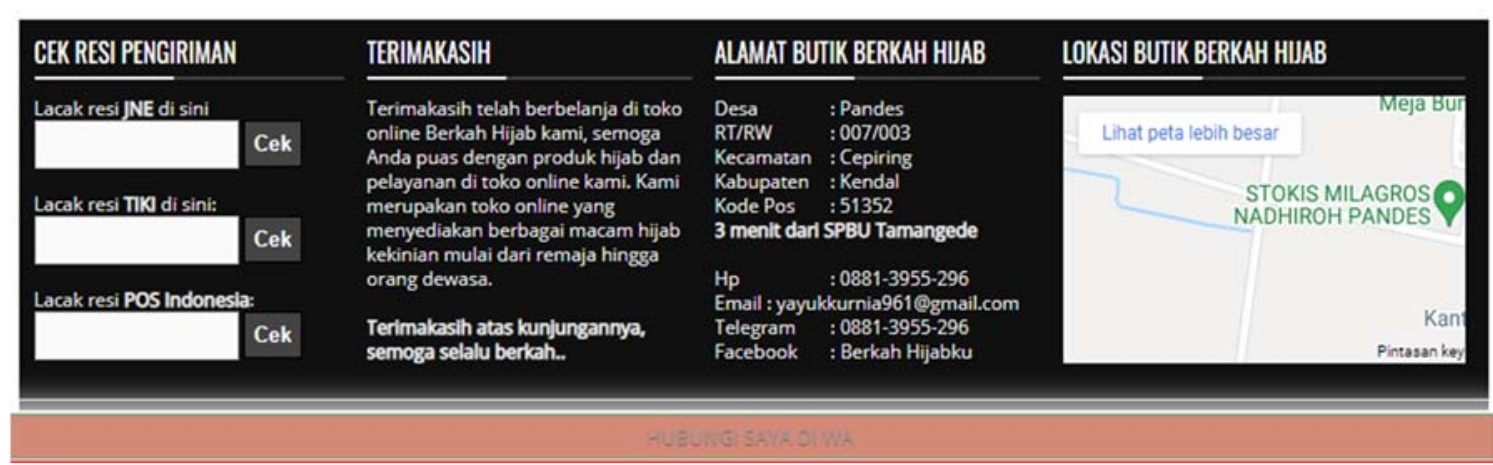

Gambar 11. Tampilan Footer dan WhatsApp Melayang

\subsection{Halaman Cara Belanja}

Pada halaman cara belanja pelanggan ditujunkan pada langkah-langkah bagaimana cara pemesanan, pembayaran hingga barang sampai ke tempat tujuan, setelah pelanggan memahami bagaimana proses pemesanan, pelanggan dapat menghubungi penjual via WhatsApp, Email dan Sms dengan mengklik salah satu button yang tersedia.

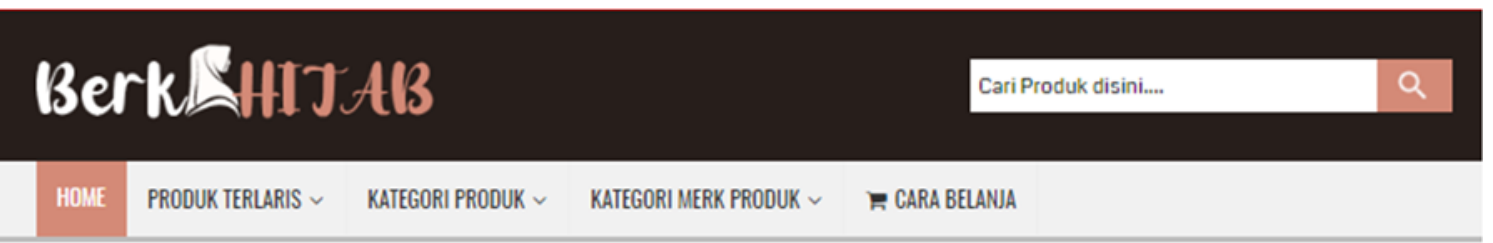

Selamat datang di Toko Kami.. Hijb merupgkan hal yang waib bsgi semua kaum wanita muslimgh. Mengapa saya memilih berualan hijab ?? Sebab saya memilih peluang dimana pada sagt ini ketertarikan kaum wanita muslim untuk mengounakan hïgb sangatlah tinogi, terutama dikalangan remaja, khususnya bagi mahasisw. Hiliab bukanlah suatu hal yang rumit, namun sudah menjadi styje bagi kalangan remaja muslim untuk menampilkan oiri khas dengan menggunakan hijab mereka tetap cantik dan tidak meninggakan norma-norma dalam sgams. Berbagai macam model hijab baik hijab segiempat, pashmina, hijab instan, hijab bergo, pashmina instan pun bermunoulan demi menkikat perhatian kaum wanita untuk melengkapi segala akivitas, mulai dari dirumah, kampus, jalan-jalan, olahraga, sampai acara kondangan maupun acara resmi.

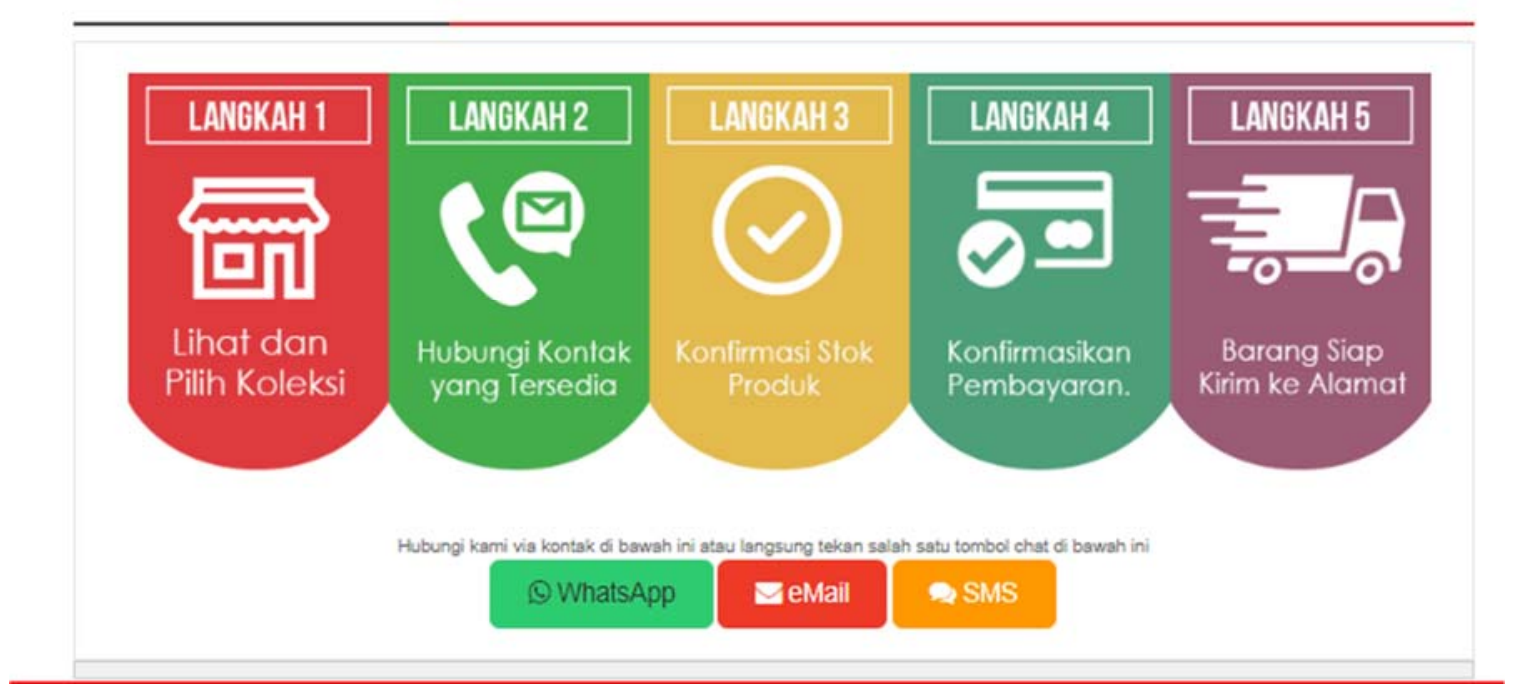

Gambar 12. Halaman Cara Belanja

Desain Web E-Commerce Berbasis Blogspot sebagai Media Promosi Butik Berkah Hijab Kendal.

(Yayuk Kurniawati) 
4. Kesimpulan dan Saran

\subsection{Kesimpulan}

a. Pembuatan blog e-commerce ini dapat mempermudah penjual mempromosikan produk hijabnya, serta memudahkan pelanggan untuk bertransaksi online sehingga tidak perlu datang langsung ke toko.

b. Penjualan hijab berbasis blog ini dapat meningkatkan efektivitas dan efisiensi penjualan pada butik berkah hijab.

c. Adanya bloge-commerce ini dapat membantu mempromosikan produk ke jangkauan yang lebih luas tidak hanya di daerah Kendal saja akan tetapi juga diluar daerah Kendal.

\subsection{Saran}

d. Sistem penjualan pada Butik Berkah Hijab hendaknya diterapkan secara bersamaan dengan sistem lama dalam masa penyesuaian sistem baru.

e. Pengelola blog e-commerce ini harus dilatih terlebih dahulu dan diberi pengetahuan tentang internet agar dapat mejalankan tugasnya dengan baik dan benar.

f. Penerapan blog e-commerce ini sebaikya dibarengi dengan sistem penjualan secara komputerisasi untuk mengelola penjualan yang terjadi di toko supaya lebih seimbang.

\section{Daftar Pustaka}

Digdowiseiso Kumba. (2019). "Teori Pembangunan”. Jakarta Selatan : Lembaga Penerbitan Universitas Nasional (LPU-UNAS).

Adhikara, Cooky Tri. (2010). "Analisis Sebaran Pemanfaatan Internet Blog/Weblog Untuk Kategori Bisnis Dan Ekonomi Di Dunia Maya Indonesia". Jakarta Barat : Jurnal ComTech.

Jamaludin, Achmad, dan Arifin Zaenul dkk. (2015). "Pengaruh Promosi Online Dan Persepsi Harga Terhadap Keputusan Pembelian (Survei Pada Pelanggan Aryka Shop di Kota Malang)”. Malang : Jurnal Administrasi Bisnis.

Achmad. (2018). "Pengaruh Pengguna E-Commerce Terhadap Transaksi Online Menggunakan Konfirmasi Faktor Analisis". Jakarta Selatan : Jurnal Saktor Exacta.

Basu Swasatha dan Irawan. (2005). "Manajemen Pemasaran Modern”. Yogyakarta : Liberty Yogyakarta.

Djaslim Saladin. (1991). "Unsur-Unsur Inti Pemasaran Dan Manajemen Pemasaran”. Bandung : Mandar Maju.

Mukaromah, Siti, dan Rosadi Dadi. (2015). "Perancangan Aplikasi E-commerce (Studi Kasus : Distributor Coklat Bandung)”. Bandung : Jurnal Computech \& Bisnis. 